\title{
ELECTROPHORETIC PATTERN OF HEREDITARY HAEMOGLOBIN DISORDERS IN BANGLADESH
}

\author{
UDDIN MK ${ }^{1}$, AZIZ MA ${ }^{2}$, SARDAR MH ${ }^{3}$, HOSSAIN MZ ${ }^{3}$, BHUYA MF $^{4}$, UDDIN MM ${ }^{5}$, KOBIR MA $^{6}$, \\ RAHMAN $\mathrm{MJ}^{7}$
}

\begin{abstract}
:
Background: Genetic defects of haemoglobin are the most common genetic disorders and affect around $7 \%$ of world Population, occur in tropical and sub tropical areas. $\beta$ thalassaemia is more common in the Mediterranian region while $\alpha$ thalassaemia is more common in the Far East.

Objective: To Find out the pattern of haemoglobin disorders and to evaluate and compare the diseases in study population.

Methods: A total number of 210 subjects with age ranged from 2 to 72 years of both sexes were included in the study. The present study was conducted in out patient department (OPD) of Haematology, Bangabandhu Sheikh Mujib Medical University (BSMMU,) Dhaka. Bangladesh. During the period of January 2007 to December 2007, patients were selected on the basis of morphological blood film examination and $\mathrm{Hb}$-electrophoresis on cellulose acetate at PH 8.6.

Results: Among the 210 Subjects, thalassaemia trait were (47.14\%), HbE-beta thalassaemia were $30.47 \%$, HbE Trait 13.3\%, HbE disease (5.71\%) and thalassaemia major were (3.33\%).

Conclusion: It is evident that, Hereditary Haemoglobin disorders are quite common in Bangladesh and this disorders are inherited as autosomal recessive Mendelian pattern affecting both male and female.
\end{abstract}

Key words: Electrophoretic pattern, Haemoglobin disorders.

J Dhaka Med. Coll. 2010; 19(1) : 39-42.

\section{Introduction:}

Hereditary haemoglobin disorders are a heterogeneous group of mendelian disorders. It includes haemoglobinopathies, characterized by structurally abnormal haemoglobin variants and thalassaemia by partial or total suppression of normal peptide chains of haemoglobin molecules. ${ }^{1}$

More than hundreds of structural haemoglobin variants have been identified in the last three decades. Majority of these results from single aminoacid substitution in one or other of the globin chains. The simple system of presumptive identification of these variants by simple electrophoresis still remain an extremely useful procedure though it does not discriminate between different mutants which carry the same electrophoresis. ${ }^{2,3,4}$ The inheritance of haemoglobin disorders follows a simple mendelian pattern. The heterozygous state for a disorder is called "trait", while the homozygous or genetic compound is called "disease". Thalasseamia is most common inherited genetic disorder and varies in different population group in the world. Haemoglobin disorders will become a major issue in developing countries like Bangladesh in this millennium. World Health Organization (WHO) estimates that at least $7 \%$ of the world population are carriers of different inherited disorder of haemoglobin. It is observed that when the world population finally stabilizes, at least $8 \%$ of the population will be carrier or Trait ${ }^{5}$. The world population of carrier of beta thalassaemia trait is reported to be more than 100 millions world wide and about 1,00,000 children with

1. Consultant, 200 Beded Hospital, Narayanganj.

2. Assistant Professor of Haematology, BSMMU, Dhaka.

3. Assistant Professor of Medicine, Dhaka Medical Collage,Dhaka.

4. Associate Professor of Haematology, Sir Salimullah Medical Collage, Dhaka.

5. Professor, Northan International Medical Collage Hospital, Dhaka.

6. Professor of Haematology, Sir Salimullah Medical Collage, Dhaka.

7. Professor \& Chairman, Department of Haematology, BSMMU, Dhaka.

Correspondence : Dr. Md. Kazim Uddin 
thalassaemia major are born each year. In Banglsdesh, there is no definite data regarding electrophoresis pattern of hereditary haemoglobin disorders. No screening program has been taken any population group. A conservative world health report estimates that $3 \%$ are carrier of Beta thalasseamia and 4\% are carriers of $\mathrm{Hb} \mathrm{E}$ in Bangladesh ${ }^{7}$. Most of the thalassaemic patients need frequent blood transfusion about every 2-3 weeks interval. As a result good percentage of blood is utilized by them, which is a major burden to the department of transfusion medicine with a lot of complication and transfusion hazards. So there is maximum chance of transmission of infectious agent like HCV, HBV, HIV, plasmodium and treponema pallidum etc.

\section{Methods:}

The present study was conducted in Out Patient Department (OPD) of Haematology Department, Bangabandhu Sheikh Mujib Medical University (BSMMU), Dhaka. Out Patient Department (OPD) of Haematology could provide adequate number of cases for this study. The study was carried out from January to December, 2007 and total No. of 210 cases of hereditary haemoglobin disorder were studied over a period of one year. As Dhaka is the capital city and receives the patients which are referred from all parts of the country, it seems that the samples roughly represent the whole population of the country. Patients were selected on the basis of morphological evidence of haemolytic anaemia in peripheral blood film and haemoglobin electrophoresis on cellulose agar acetate at PH 8.6. Age, Sex Presenting complaints and family history were noted.

\section{Result:}

Among the 210 subjects, thalassaemia trait were $(47.14 \%)$, HbE-beta thalassaemia were $30.47 \%$, HbE Trait 13.3\%, HbE disease (5.71\%) and thalassaemia major were (3.33\%)

Table-I

Distribution of population by age

\begin{tabular}{lcc}
\hline Age (years) & No. of patient & Percentage $\%$ \\
\hline$<5$ & 35 & $16.66 \%$ \\
$5-10$ & 32 & $15.23 \%$ \\
$11-20$ & 60 & $28.57 \%$ \\
$21-30$ & 56 & $26.66 \%$ \\
$>30$ & 27 & $12.88 \%$ \\
\hline
\end{tabular}

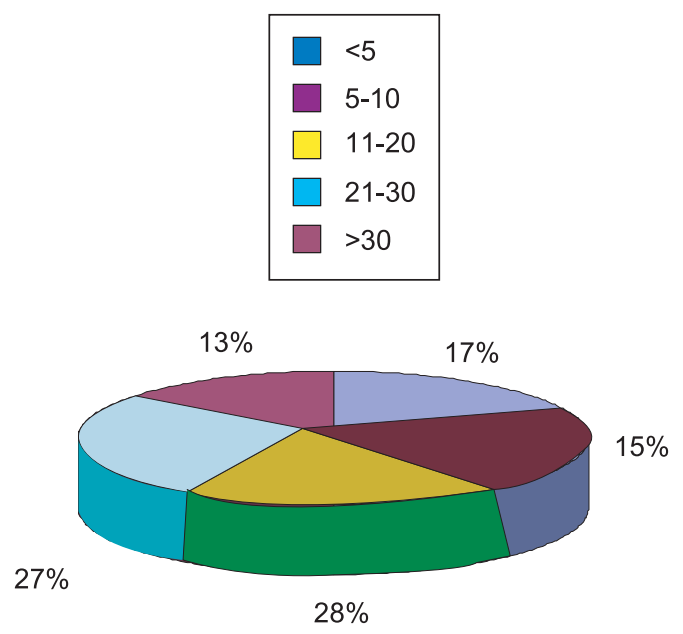

Fig. 1: Distribution of population by age

Table-II

Sex distribution

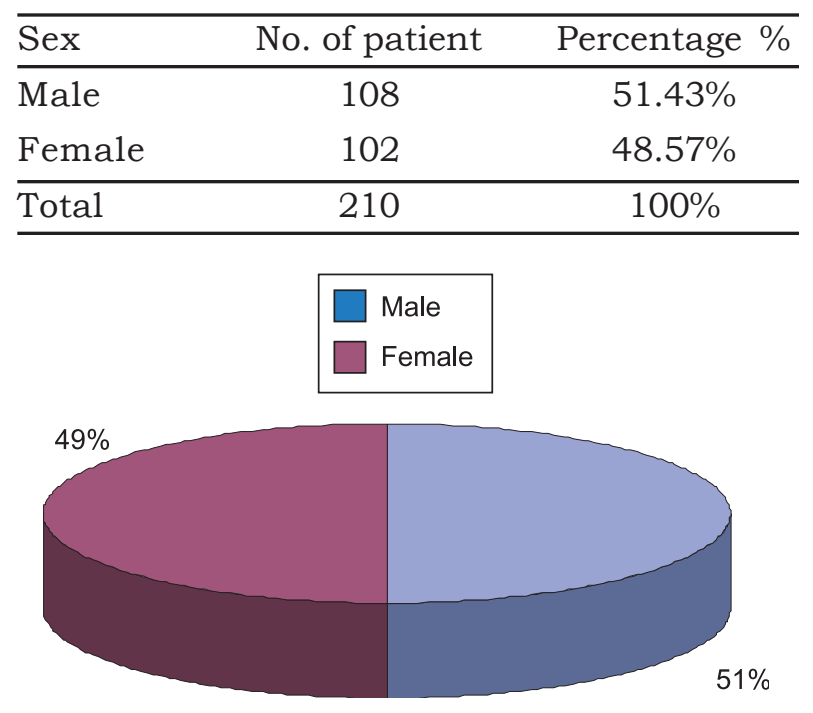

Fig. 2: Sex distribution

Table-III

Presenting clinical manifestation

\begin{tabular}{lcc}
\hline Symptoms \& sign & $\begin{array}{c}\text { No. of } \\
\text { patient }\end{array}$ & Percentage \\
\hline Weakness & 148 & $70.47 \%$ \\
Jaundice & 117 & $55.71 \%$ \\
Hepatomegaly & 84 & $40.00 \%$ \\
Splenomegaly & 143 & $60.09 \%$ \\
Fever & 76 & $36.19 \%$ \\
Retardation of growth & 27 & $12.89 \%$ \\
Pallor & 6 & $2.85 \%$ \\
Leg ulcer & 5 & $2.38 \%$ \\
Bony change & 4 & $1.48 \%$ \\
Asymptomatic & 53 & $25.23 \%$ \\
\hline
\end{tabular}



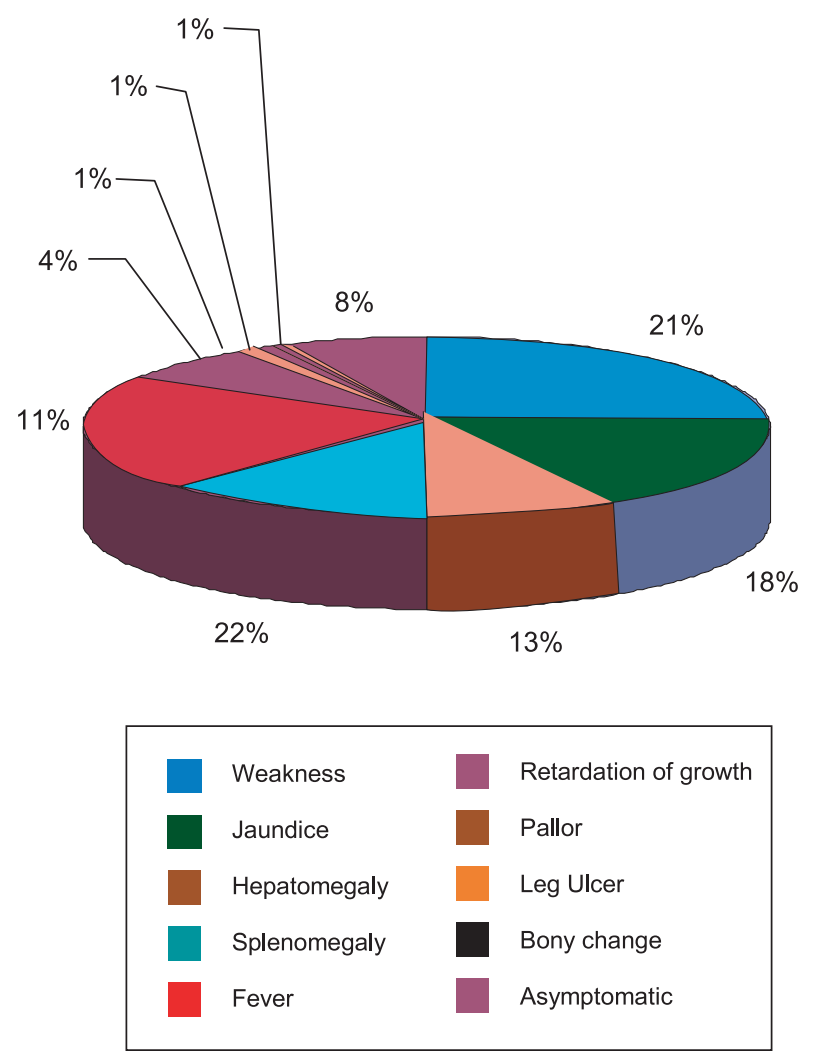

Fig.-3: Presenting clinical manifestation

Table-IV

Pattern of hereditary haemoglobin disorders.

\begin{tabular}{lcc}
\hline Symptoms \& sign & $\begin{array}{c}\text { No. of } \\
\text { patient }\end{array}$ & $\begin{array}{c}\text { Percentage } \\
\%\end{array}$ \\
\hline Beta-thalassaemia trait & 99 & $47.14 \%$ \\
Hb- E-beta thalassaemia & 65 & $30.47 \%$ \\
Hb-E-Trait & 28 & $13.33 \%$ \\
Hb-E disease & 12 & $5.71 \%$ \\
Beta-thalassaemia Major & 7 & $3.33 \%$ \\
\hline
\end{tabular}

\section{Discussion:}

In this study, heterozygous $\alpha$ thalassaemia was found most common. Double heterozygous HbEbeta thalassaemia and heterozygous $\mathrm{HbE}$ were next most common. Similar findings were observed in the others studies. ${ }^{5,8}$ In our country, data regarding the hereditary haemoglobin disorder are not available so far, but in our neighboring countries in Myanmar and India, they have got their prevalence rate. Bangladesh is in geographical continuity with Myanmar, Assam (India), West Bengal (India),

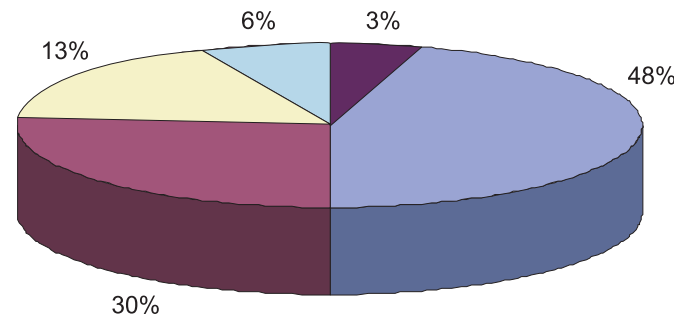

Beta-thalassacmia trait

$\mathrm{Hb}-\mathrm{E}$ - beta thalasseunia

Hb-E-Trait

$\mathrm{Hb}-\mathrm{E}$ disease

Beta-thalassemia Major

Fig.-4: Pattern of hereditary haemoglobin disorders.

Tripura and also same belt of Thailand and Combodia. The population of West Bengal, Assam and Myanmar share the same ancestry with that of Bangladesh. In North Eastern, the $\mathrm{HbE}$ gene reaches the frequencies of about $7.5 \%{ }^{9}$, in Myanmar it is about $10-20 \%$ and in Assam it is $30 \%$. As Bangladesh is situated in Between all these area and the people might have been migrated from these areas to Bangladesh in decades earlier. In this study observed that the prevalence rate of $\mathrm{HbE}$ gene $(13.33 \%)$ is quite similar to other neighboring countries. In one study in West Bengal (Kolkata) showed that the prevalence of $\alpha$ thalassaemia trait alone to be $7.5 \%$ and it is much higher $12.6 \%$ in Orissa (India) ${ }^{10}$. It can compare this observation regarding the incidence as it also correlates well with some of the small studies done in Bangladesh on hereditary haemolytic anaemia ${ }^{11}$. But incidence as well as percentage study is varied because this present study was done only from pattern of electrophoresis in cellulose agar acetate at $\mathrm{P}^{\mathrm{H}}$ 8.6. Within this small study group, $\mathrm{HbE} \alpha$ thalassaemia and $\mathrm{HbE}$ trait have taken a place. It is observed from other studies that double heterozygous $\mathrm{Hb}-\mathrm{E}$ beta thalassaemia was the commonest thalassaemia syndrome ${ }^{11,12}$. Disorders are manifested at all ages from minimum 1.5 years 
to 72 years. The highest incidence is in the second decade $(28.37 \%)$. The age distribution shown in the table is roughly correlated by other study. ${ }^{12}$

\section{Conclusion:}

It is evident from this study that the hereditary haemoglobin disorders are quite common in Bangladesh and these disorders are inherited as autosomal recessive mendelian pattern affecting both male $\&$ female. So we can not avoid these diseases. In this study, we got heterozygous (trait) like both heterozygous thalassaemia and heterozygous $\mathrm{HbE}$ trait significant number in camouflage. This population is usually asymptomatic, do not require treatment and lead a reasonably good quality of life but they are dangerous because of possibility of homozygous or double heterozygous inheritance through marriage of unaware couples or silent spread as trait. This is a serious health threat to our nation, if it is allowed to continue without taking measures for prevention. Finally in spite of all limitations of the study we have at least reached a concrete conclusion that hereditary haemoglobin disorders are very common in Bangladesh, on which the health authorities should focus. An awareness has to be created at the national level to reduce the incidence of hereditary haemoglobin disorders in community. It is mandatory to detect the trait in general population with large scale and proper genetic counseling should be ensured. It is time to think about the molecular and prenatal diagnosis to start and to prevent the further spread of the disease.

\section{Acknowledgement:}

This work was supported by Department of Haematology, Bangabandhu Sheikh Mujib Medical University (BSMMU), Dhaka.

\section{References:}

1. Ball S. Congenital disorders of haemoglobin and blood cells. Medicine. 2004; 32(5): 20-7.

2. Kattak MF, Saleem M. Structural haemoglobin variants in adult healthy population of Northern Pakistan. Pakistan J Pathol. 1992; 3(2): 85-7.

3. ICSH: Recommendation for selected method of haemoglobin $\mathrm{A}_{2}$, A \& $\mathrm{HbA}_{2}$ reference preparation. $\mathrm{Br} \mathrm{J}$ Haematol. 1978; 38: 573-8.

4. Fishlidar AJ, Hoffman GC. A practical approach to detection of hemoglobinopathies; Part-III. Lab Med. 1987; 18: 513.

5. Khan WA. Thalassaemia in Bangladesh. Dhaka Shishu Hosp J. 1999; 15: 42-4.

6. APOGI for the haemoglobin disorders. 1998 May; (Evaluation) release.

7. WHO guidelines for control of haemoglobin disorders. Unpublished document WHO/HDP/ $\mathrm{HB} / \mathrm{GL} / 94$. Obtainable free of charge from the hereditary disease program, WHO, Geneva, Switzerland.

8. Dacies SJ. The haemolytic anaemia. Vol-2. $3^{\text {rd }}$ ed. New York: Churchill Livingstone; 1988. p.285399.

9. Choudhury AR, Joardar M, Sen S, Talukder G, Sharma A. Haemoglobin variants of West Bengal. J Indian Med Assoc. 1988; 86(2): 31-3.

10. Misra RC, Ram B, Mohapatra BC, Das SN, Misra SCM. High Prevalence of heterogenecities of thalassaemia in Orissa. Indian J Med Res. 1991; 94: 931-4.

11. Haque MS. Alam MA. Khan WA. Thalassaemia situation in Dhaka Sishu Hospital. Dhaka Shishu Hosp J. 1999; 15: 30-6.

12. Mahmud Z, Rahman M, Rashid MA. Pattern of haemolytic anaemia in Bangladesh. Bangladesh Armed Forces Med J. 1999; 25: 21-6. 